\title{
Polymer microarray technology for stem cell engineering
}

Robert Coyle ${ }^{1,2}$, Jia Jia ${ }^{1,2}$, Ying $\mathrm{Mei}^{1,2,{ }^{*}}$

\author{
${ }^{1}$ Bioengineering Department, Clemson University, Clemson, SC 29634, USA \\ ${ }^{2}$ Department of Regenerative Medicine and Cell Biology, Medical University of South Carolina, Charleston, SC 29425, \\ USA \\ *Corresponding author: mei@clemson.edu \\ R. C and J. J have made equal contributions to the manuscript.
}




\section{Introduction}

Stem cells hold remarkable potential for applications in regenerative medicine and disease modeling. They have the unique ability to undergo self-renewal in an undifferentiated state, as well as the potential to differentiate into multiple cell types [1-4]. Adult stem cells, such as hematopoietic stem cells (HSCs) and mesenchymal stem cells (MSCs), have been thoroughly investigated, with their clinical benefits having been well established [5-7]. The recently derived human pluripotent stem cells (hPSCs), including both human embryonic stem cells (hESCs) and human induced pluripotent stem cells (hIPSCs), have the ability to both self-renew indefinitely and differentiate into all the human cell types in vitro [8-11]. With these enabling characteristics, hPSCs provide an ideal source for the large number of cells ( $>10^{\wedge} 9$ cells / patient) needed for cell replacement therapies and tissue engineering applications [12-14].

To direct differentiation of hPSCs, many of the early advances were accomplished through the study of embryology, with the intent of replicating embryo development [15-17]. Through the use of soluble inductive factors (e.g., growth factors and small molecules) to recapitulate embryonic stage cell signaling, hPSCs can be differentiated into a desired cell phenotype. One textbook example is to modulate Wnt signaling in a temporally defined manner to produce functional cardiomyocytes from hPSCs [18]. In addition to this rational-design based strategy, high throughput approaches have been utilized to screen small molecules, growth factors, as well as their combinations, to direct hPSC differentiations [19]. For example, Borowiak et al. screened 4,000 small molecules to identify two molecules capable of directing hESCs into endodermal cells [20]. With these findings, soluble factors have been extensively utilized to derive hPSCs into various functional cells.

In addition to the soluble factors, insoluble factors (e.g., cell culture substrates and 3D scaffolds) have been shown to have controlling effects on stem cells [17, 21, 22]. While soluble factors can modulate specific target(s) in signaling pathways to influence stem cells via chemical interactions, insoluble factors can provide both chemical and physical cues to direct stem cell fate $[17,23-26]$. As shown in Figure 1, signals provided by the materials can be separated into two categories: surface bound chemical structures and material physical properties [27]. Surface bound chemical structures can engage a variety of cell membrane-bound proteins and receptors to initiate various cellular signaling cascades and influence stem cell activities [28]. These surface bound bioactive molecules can be derived from a variety of sources. Some studies have utilized naturally derived extracellular matrix (ECM) proteins (e.g., Fibronectin and Laminin) due to their biological functions and abundant presence in the extracellular space in the human body [29]. Other research has suggested that it is advantageous to utilize the effective groups of these proteins in order to increase efficiency [30]. This has led to the popularity of peptide-mediated stem cell adhesion and fate determination. One example is the RGD peptide sequence that is known for its ability to induce adhesion [31, 32]. Though integrin has a high affinity for RGD, the resulting interaction alone is not sufficient to control cell fate, requiring a combination of different ligands to elicit an optimized response from the cell membrane [33, 34].

During the past decade, the study of the effects of material physical properties on stem cells has received significant attention. One facet is the use of nanoscale topographical features to modulate cell adhesion and direct stem cell fate [35, 36]. Due to the high-binding affinity of integrin and its ability to produce focal adhesion points through cell-surface interaction, cells can bind surfaces of varying roughness and patterned geometries. It has been shown that nanotopographic features of a material's surface can influence the key steps in cell adhesion, influencing stem cell fate determination (i.e., self-renewal and directed differentiation) [37-39]. In addition to nanotopographical features, it has been shown that cells are sensitive to the 
microscale features and stiffness of the material surface $[40,41]$. Both the microscale features and materials stiffness can alter the cellular cytoskeletal structures and affect stem cell fate [4143]. Due to the wide variety of chemical and physical properties capable of influencing cell behavior, it is necessary to develop a highly tunable platform with the capacity to assess individual conditions in an efficient manner.

The traditional model for discovering effective factors for materials-directed cell activity and fate determination utilizes a methodical approach, where only a few conditions can be thoroughly investigated at a time [44]. Given the complexity of these (stem) cell-material interactions, there is a growing need for the development of high throughput approaches for the quick and efficient determination of optimal materials properties. One such strategy is the use of surface gradients, where the material is spatially arranged into regions of gradually varied chemical concentrations or physical properties [45-48]. These methods allow for the rapid establishment of relationships between one or two materials properties and (stem) cell behaviors. Other studies leveraged the recent advancements in robotic technology and microfabrication to develop polymer microarray systems to rapidly examine a variety of tunable testing conditions $[44,49,50]$. These strategies include the utilization of robotic liquid-handling systems to spot monomer or polymer solutions in an evenly spaced and reproducible manner to create polymer microarrays [51-53]. These polymer arrays can facilitate the simultaneous screening of a variety of factors, allowing for sideby-side analysis and small-scale experiments that require relatively few resources.

In this review, we will summarize recent developments in polymer array technology and their applications in stem cell engineering. First, we will discuss the advancements in polymer microarray technology to screen the effects of material chemical structures on stem cells. We will then describe the application of these microarrays to examining the effects of materials physical properties on stem cells, with an emphasis on surface topography and elastic modulus. Lastly, we will review microarrays capable of examining the combined effects of materials chemical structures and physical properties in eliciting desired cell responses.

\section{Screening the effects of materials chemical structures on stem cells}

\subsection{Combinatorial synthetic polymer microarrays}

One application of the polymer microarray technology is to rapidly identify synthetic substrates for hPSC culture through the screening of microspotted materials with diverse properties and characteristics. To this end, we have developed a library of 496 different materials constructed by 22 acrylate monomers, accomplished using robotic liquid handling technology and UV photopolymerization. Physical characteristics including surface wettability, surface roughness, and indentational elastic modulus were quantified using high throughput methods. This allowed for the establishment of a structure-function relationship between the biological performance of the hESC culture and the material properties [51]. The results showed that the substrate properties affected the undifferentiated hESCs to different degrees, with the surface chemistry showing more pronounced control over the cells, as opposed to material properties like roughness or the elastic modulus (Fig. 2). The surface chemistry, especially esters and hydrocarbons, were recognized as key cues on materials surface to promote hES cell selfrenewal, with the optimal surface effectively enhancing adsorption of vitronectin to improve selfrenewal of hPSCs. Enlightened by this information, we have developed an ultraviolet/ozone radiation modified polystyrene (PS) culture system in the hopes of producing a favorable cell culture environment. It is possible to introduce certain chemical cues that have been shown to promote hESC self-renewal, such as hydrocarbons and ester/carboxylic acid, by treating PS with an optimized dose of short wavelength UV (Fig. 3) [54]. UV exposed PS (UVPS) surfaces were able to produce three folds more cells per area when compared to the more commonly 
used mouse embryonic fibroblast (mEF) feeder cells. Further investigation has revealed that UVPS can promote vitronectin adsorption, improving surface interaction with integrin $\alpha_{v} \beta_{3}$ and $\alpha_{v} \beta_{5}$ to better support hPSCs self-renewal.

Recently, Celiz et al. expanded this system to include 141 different monomers in a microarray format for screening the culture substrates to support hPSC adhesion and expansion. This system has allowed for the identification of several new chemical moieties that can promote hPSC adhesion [55]. The current methods to passage hESCs and hIPSCs (e.g., proteolytic enzymatic digestion) are very inefficient and tend to result in cellular abnormality. To improve this, Zhang et al. prepared a 2-(diethylamino)ethyl acrylate based thermoresponsive hydrogel array to support passaging hESCs in a reagent-free manner. From the developed library, the authors identified a hydrogel that can support long-term expansion (2-6 months) of hESCs and allow for reagent-free cell passaging by simply changing the culture temperature from 37 to 15 ${ }^{0} \mathrm{C}$ for $30 \mathrm{~min}$ [56].

In addition to identifying substrates for hPSC culture, Celiz, Harrington and Hook went on to use 116 polymers to determine the best substrates for supporting attachment of fibroblastic MRC4 and epithelial Calu3 cells. One of these polymer surface conditions showed the successful attachment of epithelial cells and fibroblasts, which suggested their potential applications in lung tissue engineering [57]. They went on to use this technology in printing existing polymers and their combinations onto a microarray. Anderson et al. designed a microarray system composed of a number of biodegradable polymers and explored their effects on human mesenchymal stem cells (hMSCs), neural stem cells (NSCs) and primary articular chondrocytes [50].

Using comparable methods, Hay and coworkers were able to screen potential substrates for hESC-derived hepatocytes (hESC-HE) culture by spotting 380 presynthesized polyurethanes and polyacrylates onto agarose coated glass slides [58]. The system revealed six polymers that could support hESC-HE attachment, but neither chemical nor physical cues were found to elicit biological responses. This highlights the need for unbiased screening to discover suitable substrates for the culturing of stem cells. The best condition was found to be a polyurethane coated with a clinically approved, bioartificial liver matrix, shown to be able to maintain in vitro hepatic phenotype and function.

\subsection{Combinatorial ECM protein microarrays}

In addition to the synthetic polymers, ECM proteins provide another source for the construction of a combinatorial library. Despite being relatively expensive and possible contaminants of animal origin, they hold great potential in having more potent signaling moieties capable of initiating cellular signaling cascades to regulate stem cell growth and differentiation. As early as 2000, MacBeth et al. developed protein microarray technology [59]. Then, Flaim et al. fabricated ECM protein microarrays for studying mouse embryonic stem (mES) cells and hepatocytes, revealing the effects of different protein combinations on hepatocyte function and $\mathrm{mES}$ cell differentiation. Through the use of "factorial analysis methods", the role of each ECM protein was identified and isolated from the combination as a whole. The results showed that collagen III and laminin caused down regulation of albumin (a liver-specific function marker), while collagen IV and fibronectin could lead to an increase of intracellular albumin expression [60]. Further, the group used this technology to study the combinatorial effects of ECM proteins and growth factors [61]. To this end, the authors designed microarrays composed of 20 combinations of 5 ECM proteins (fibronectin, laminin, collagen I, collagen III, collagen IV) and arranged them into a multiwell system. For this microarray, 12 different growth factors were mixed and added into microwells, allowing for the simultaneous study of 1200 experiments on 
240 unique signaling environments. This assay offered a method for the rapid identification of co-signaling between ECM protein, growth factors, and combination of the two.

Rather than focusing on combined usage of soluble growth factors, Soen et al. developed a non-contact, piezoelectric array to study the effects of premixed, printed combinations of growth factors, ECM components, cell adhesion molecules, and morphogens onto an array system, studying the proliferation and differentiation of primary bipotent human neural precursor cells [62]. Brafman et al. developed a similar strategy, producing an extended arrayed cellular microenvironment (ACMEs) [63]. Besides growth factors and ECM proteins, ACMEs also contains glycans, carbohydrate chains which organize many materials around the cells, with the authors having already applied the technology to multiple hESC and hIPSC lines.

Automated spotting systems have been extensively utilized to fabricate both synthetic polymer and ECM protein microarrays. One example of these systems is the robotic-spotted miniaturized cell-laden gel array designed by Khadmhosseini and coworkers. They evaluated the osteogenic differentiation of hMSCs in the combinations of gelatin, fibronectin, laminin, and osteocalcin with 8 kinds of media, resulting in 96 testing conditions. After identifying the optimized condition, they translated the system into a 3D macroscale hydrogel to further support the results [64]. Ghaemi and coworkers developed another robotic microarray spotted system, where silicatefunctionalized glass slides enabled the covalent immobilization of ECM proteins. Later, the surface was passivated by bovine serum albumin or poly (ethylene glycol) bisamine with different molecule weight. With this system, they successfully studied hMSCs adhesion and cell pattern integrity for up to 3 weeks of culture [65]. An alternative system with great potential is the polymer pen lithography array. This system, designed by Cabezas and coworkers, is a cantilever-free scanning probe lithographic method, capable of generating patterns on large areas. With this system, they successfully fabricated an array composed of ECM proteins (fibronectin) and studied their effects on MSCs' osteogenic differentiation [66].

ECM proteins and growth factors hold great potential for their ability to control stem cells. However, their applications could potentially be limited by their high costs, batch-to-batch variations and contaminants of animal origin. In contrast, functional synthetic materials can be made at low cost and with high purity. With recent advances in organic synthesis and chemical biology, it will be possible to screen for functional synthetic materials capable of better and more directed stem cell interaction.

\subsection{Peptide Microarray}

To develop synthetic substrates with defined biological functions, some researchers have moved to conjugate peptides (i.e., functional segments of ECM proteins) onto substrates in a microarray format. One of the common array systems used in these studies are the selfassembling monolayer (SAM) peptide microarrays. Kiessling and coworkers have developed one SAM microarray for the study of peptides derived from laminin, due to its known ability to maintain hESC pluripotence (Fig. 3) [67]. The group went on to utilize the phage display system to identify novel cell-binding peptides for hESC undifferentiated growth [68]. Next, they applied the SAM peptide microarrays to heparin-binding peptides that target to cell-membrane glycosaminoglycans (GAGs) to maintain long-term self-renewal of multiple hPSC lines [34]. Recently, this group applied the heparin-binding peptides discovered by SAM screening system to hPSC differentiation and elucidated the signal pathways switch between Akt and Smad for different germ layer cell differentiation [52].

Koepsel et al. have developed another SAM peptide array system to study the effects of multiple peptides on hMSC activities by engaging multiple cellular receptors, including integrin, bone morphogenic protein (BMP)-2 receptor and growth factor receptors [69]. Kilian's group 
developed a SAM peptide array, combined with "click" chemistry and designed to target integrin, to study the human adipose-derived stem cells (ADSCs) attachment abilities on four ECM adhesion peptides (YIGSR, GRGDS, KPSSAPTQLN and KRSR) and their various combinations. They demonstrate enhanced osteogenic expression of ADSCs through KPPSAPTQLN peptides, which provided evidence of the peptide's role in osteogenic differentiation [70].

In addition to the SAM design, there are also other peptide array generating systems, with one example being the Murphy group's PEG hydrogel array (Fig. 4) [53]. They used PEGnorbornene with the peptide as the main skeleton and PEG-dithiol as a crosslinker to fabricate the hydrogel array. The results of VEGFR2 peptide and CRGDS peptide with HUVEC showed the synergistic effects and the dependence on peptide concentration. In summary, these studies have clearly demonstrated the power of peptides as synthetic signaling molecules to modulate stem cell differentiation and activity.

\subsection{Small-molecule microarrays}

Another potential method to direct stem cell differentiation is to employ small molecules that mimic chemical aspects of the native ECM. Using this strategy, Benoit and coworkers developed a hydrogel microarray with small molecules that could emulate the functional groups of various extracellular microenvironments to induce hMSC differentiation [71]. hMSCs are well known to possess the ability to differentiate into multiple cell types, including cartilage, bone and fat. The researchers chose each of the following for their roles in connective tissue development: pedant carboxyl groups that resemble glycosaminoglycans in cartilage, phosphate groups that induce bone mineralization, and tert-butyl groups that mimic the lipid rich environment of adipose tissue. In line with their hypothesis, these functionalized hydrogels were able to induce differentiation of hMSCs into chondrogenic, osteogenic or adipogenic cells.

\section{Assessing the effects of materials physical properties on stem cells}

\subsection{Topographical biomaterials}

One important facet of research investigating the effects of materials' physical properties is the study of material topographical features. It has been shown that cells are able to respond to the nanotopographical features of different materials using integrin receptors through the process of developing focal adhesion points [39]. In order to best utilize these cell-surface interactions to direct stem cells, significant research has been devoted to investigating the governing mechanisms behind the interplay between integrin-ligand binding and nanotopography. To this end, Dalby and coworkers showed that the interactions between cells and nanoscale substrates are in a large extent mediated by cellular constructs called nanopodia, smaller and more sensitive versions of cellular filopodia [72]. In addition, they have developed an array system to investigate the effects of nanotopography on hMSC self-renewal and differentiation. Using a PMMA nanoarray with a controlled disorder (i.e., neither highly ordered nor random), they were able to direct osteogenesis in hMSCs with comparable efficiency to osteogenic media (Fig. 5) $[39,73]$. Through further investigation, the authors showed that the high ordered nanostructures reduce hMSCs adhesion, yet promote their self-renewal [74]. The altered cell adhesion on the nanoscale substrates has been determined as a major influence on stem cell fate determination. In addition, the authors applied metabolomics methodology to help understand the effects of the nanoscale substrates on hMSC multipotency, with the goal being to systematically identify useful pluripotent factors [75].

One emerging application of nanotopographic substrates for stem cell engineering is cell sorting. Chen and coworkers utilized established etching methodology to produce nanorough patterns on an otherwise smooth glass surface. They have demonstrated that the undifferentiated 
hESCs prefer smooth surfaces, while the differentiated hESCs favorably attach to nanorough surfaces. When a mixed cell population of hESCs and NIH 3T3 fibroblasts were applied to the glass slides, the cells sorted themselves according to the rough and smooth regions, with the majority of hESCs attaching to the smooth surface and the fibroblasts attaching to the nanorough surface [76].

In addition to nanotopography, stem cells can be readily manipulated using microscale substrates. It is important to make note of the difference in scale between features found on the nano- and microscale patterning. The nanoscale patterning operates on the same scale as the individual cell receptors, which allows for the nanotopographical features to directly modulate the binding activities of integrin and other adhesion protein receptors [38]. On the other hand, microscale topography deals on the scale of the cell as a whole. As a result, the microscale substrates can control stem cell size and shape, which can in turn affect cellular cytoskeletal contractility and determine stem cell phenotype [41, 43, 77].

Given the near infinite possibilities of different microscale topograghic features and their combinations, it is necessary to develop high throughput screening systems to identify the best possible combination of topographical features that can determine stem cell fate. Unadkat et al. developed an unbiased algorithm for producing topographical geometries. These 'Topochip' assays could produce 2176 random topographies, upon which hMSCs were seeded and assessed for expression of different differentiation markers (Fig. 6) [78]. The chips were made from poly(DL-lactic acid) (PLA), with individual features being $5 \mu \mathrm{m}$ and the walls being $20 \mu \mathrm{m}$. Using this system, the researchers were able to screen for patterns that improved osteogenic differentiation and cell proliferation. They have since improved upon this model by developing a chip carrier system that allows for a controlled culturing environment, eliminating many variables that may otherwise influence adhesion and development [79].

\subsection{Stiffness of substrates}

In addition to topography, one tunable physical characteristic that affects stem cell fate is the elastic modulus of substrates. The influences of substrate stiffness on stem cells are mediated through cellular cytoskeleton. It is possible to envision that cells may deform soft substrates with relative ease, while stiff surfaces force the cells to spread. This will directly influence cellular cytoskeletal contractility and influence stem cell fate [80]. Recent findings from Swift et al. further suggested that outside mechanical forces are transducted as far as the nucleus, where nucleoskeletal protein lamin-a expression scales relative to outside tissue stiffness [81].

As a pioneer in the field, Engler and coworkers demonstrated that hydrogel stiffness can effectively influence the differentiation process of hMSCs by replicating in vivo tissue elasticity. Their results showed that gels similar to muscle elasticity led to myogenic differentiation, while gels similar to calcified bone elasticity led to osteogenic differentation [82]. In addition, Musah and coworkers showed neurons can be derived from hESCs and hIPSCs using compliant hydrogel substrates [83]. Due to the limited knowledge of the adult stem cell niche in vivo, it is very challenging to expand adult stem cells in vitro [84]. To address this, Blau and coworkers showed through a microarray system that it was possible to maintain muscle stem cells (MuSCs) for longer periods of time using laminin modified PEG hydrogels with comparable elasticity to that of skeletal muscle (Fig. 7) [85]. They further developed this technology to improve transplantation efficacy in aged stem cells through the use of hydrogels with appropriate elasticity [86].

\section{Simultaneously testing the effects of chemical and physical cues}


While the array systems described above provide insight on cell activity, the singular control of physical or chemical parameters may not be sufficient to elicit the desired stem cell phenotypic responses for tissue engineering purposes. The combined testing of chemical and physical cues in an array format has emerged as a powerful strategy to screen stem cells. For example, several of the previously mentioned studies investigated not only the effects of protein or stiffness mediated cell adhesion, but also attempted varying the stiffness for the different concentrations of conjugated proteins $[51,53,81]$.

One textbook example to study biochemical and biophysical effectors of stem cells using a highthroughput microarray system was developed by Gobaa et al. They utilized a robotic spotting system to examine different combinations of adhesive proteins on increasingly stiff hydrogel surfaces [87]. The authors further modified this technology for individual cell sorting, which allowed for the building of custom live mammalian cell arrays for the culture and interrogation of cell libraries [88]. Through the careful integration of hydrogels with varying stiffness, roughness, or hydrophobicity, it may be possible to induce a wider variety of responses that would otherwise be difficult to access through one parameter alone.

In another example, Lee et al. developed a novel microarray to investigate the combined effects of cell geometry, hydrogel substrate mechanics and cell adhesive ligand composition on hMSC differentiation [89]. In addition to hydrogel systems, Weng and coworkers developed a micropost array, which contains ECM protein-coated PDMS microposts with varied the length, diameter, spacing, and stiffness to understand the synergistic effects of matrix stiffness and surface bounded cell adhesive ligands. This PDMS micropost array can allow the authors to independently control and completely decouple substrates' chemical and physical properties, including cell adhesive ligand density and pattern, as well as bulk and nanoscale mechanics of the substrates [90].

While most of the above-described microarray systems are limited to 2D substrates, recent research has shifted to prepare 3D culture environments. The goal of this strategy is to better understand stem cell behavior through the development of a more in vivo-like environment. To this end, Ranga et al. utilized a liquid-dispensing robot to prepare 3D hydrogel microarrays that were used to test the combined effects of matrix elasticity, proteolytic degradability, and signaling proteins on the self-renewal of mESCs (Fig. 8) [91]. Another potentially powerful strategy to fabricate 3D hydrogel microarray is to utilize photolithography to pattern adhesion peptides, eliciting specific responses from cell cultures. For example, Mosiewicz et al. produced a hydrogel that could be selectively photoactivated to bind a variety of cell responsive proteins and peptide sequences to manipulate stem cells in 3D environments [92].

\section{Perspective and conclusion}

To date, one of the largest problems facing hPSC technology in tissue engineering applications is the difficulty in producing large numbers of patient specific, functional cells. Despite the progress made in optimizing soluble factors (e.g., chemically defined media) for hPSC selfrenewal and differentiation, Matrigel, an extract from mouse tumors, has remained the gold standard as a substrate for hPSC culture and differentiation. Due to the complexity of the chemical/biological compositions (>1800 proteins) of Matrigel, it is expected that high throughput microarray technology will play a vital role in the discovery of chemically defined substrates for hPSC culture. For example, Kiessling and coworkers employed the microarray strategy to develop peptide-based substrates binding to cell membrane-bound GAGs for hPSCs' self-renewal and directed differentiation $[68,93]$. Given the large variation between different hESCs and hIPSC lines [94, 95], it is anticipated that each hESC and hiPSC line may need its own synthetic substrates for expansion and differentiation. This will necessitate the further 
development and wide application of polymer microarray technology in personalized/precision regenerative medicine and disease modeling.

In addition to hPSCs, very recent research has clearly demonstrated the power of adult stem cells in regenerative medicine [96, 97]. Due to the limited understanding of adult stem cell niche in vivo, it is very difficult to isolate and expand most human adult stem cell lines. The microarray technology can dramatically accelerate the discovery of innovative materials to facilitate the development of adult stem cell mediated regenerative medicine.

Most research to date has been limited in developing culture substrates for stem cells, with the paradigm in stem cell research gradually shifting from cell production to cell delivery and integration of delivered (stem) cells with host tissues. Although human cardiomyocytes can be routinely derived from hESCs and hiPSCs, only $\sim 10 \%$ hiPSC-derived cardiomyoytes have been found to be viable after they were injected into infarcted myocardium $[98,99]$. This clearly demonstrates an unmet need to rapidly develop three-dimensional, semi-vivo systems to understand and engineer stem cell behaviors in physiological and pathological environments. The further development of robotic liquid handling technology, hydrogel chemistry, and photolithography would greatly accelerate the development of three-dimensional, matrix-like scaffolds for stem cell engineering [35, 100, 101].

\section{Acknowledgement}

The authors would like to thank the financial support from the National Institutes of Health (8P20 GM103444, U54 GM104941), the startup funds from Clemson University, the National Science Foundation (NSF - EPS-0903795), and the NIH Cardiovascular Training Grant (T32 HL007260).

\section{References:}

[1] Weissman I. Stem cell therapies could change medicine... if they get the chance. Cell stem cell 2012;10:663-5.

[2] Daley GQ. The promise and perils of stem cell therapeutics. Cell stem cell 2012;10:740-9. [3] Melton DA. Using stem cells to study and possibly treat type 1 diabetes. Philosophical transactions of the Royal Society of London Series B, Biological sciences 2011;366:2307-11. [4] Saha K, Jaenisch R. Technical challenges in using human induced pluripotent stem cells to model disease. Cell stem cell 2009;5:584-95.

[5] Martinez EC, Kofidis T. Adult stem cells for cardiac tissue engineering. Journal of molecular and cellular cardiology 2011;50:312-9.

[6] Pittenger MF, Mackay AM, Beck SC, Jaiswal RK, Douglas R, Mosca JD, et al. Multilineage potential of adult human mesenchymal stem cells. Science 1999;284:143-7.

[7] Weissman IL, Anderson DJ, Gage F. Stem and progenitor cells: origins, phenotypes, lineage commitments, and transdifferentiations. Annual review of cell and developmental biology 2001;17:387-403.

[8] Takahashi K, Tanabe K, Ohnuki M, Narita M, Ichisaka T, Tomoda K, et al. Induction of pluripotent stem cells from adult human fibroblasts by defined factors. Cell 2007;131:861-72.

[9] Takahashi K, Yamanaka S. Induction of pluripotent stem cells from mouse embryonic and adult fibroblast cultures by defined factors. Cell 2006;126:663-76.

[10] Thomson JA. Embryonic Stem Cell Lines Derived from Human Blastocysts. Science 1998;282:1145-7.

[11] Yu J, Vodyanik MA, Smuga-Otto K, Antosiewicz-Bourget J, Frane JL, Tian S, et al. Induced pluripotent stem cell lines derived from human somatic cells. Science 2007;318:1917-20.

[12] Shiba Y, Hauch KD, Laflamme MA. Cardiac applications for human pluripotent stem cells. Current pharmaceutical design 2009;15:2791-806. 
[13] Mignone JL, Kreutziger KL, Paige SL, Murry CE. Cardiogenesis from human embryonic stem cells. Circulation journal : official journal of the Japanese Circulation Society 2010;74:2517-26.

[14] Laflamme MA, Zbinden S, Epstein SE, Murry CE. Cell-based therapy for myocardial ischemia and infarction: pathophysiological mechanisms. Annual review of pathology 2007;2:307-39.

[15] Heng BC, Haider H, Sim EK, Cao T, Ng SC. Strategies for directing the differentiation of stem cells into the cardiomyogenic lineage in vitro. Cardiovascular research 2004;62:34-42. [16] Murry CE, Keller G. Differentiation of embryonic stem cells to clinically relevant populations: lessons from embryonic development. Cell 2008;132:661-80.

[17] Discher DE, Mooney DJ, Zandstra PW. Growth factors, matrices, and forces combine and control stem cells. Science 2009;324:1673-7.

[18] Ueno S, Weidinger G, Osugi T, Kohn AD, Golob JL, Pabon L, et al. Biphasic role for Wnt/beta-catenin signaling in cardiac specification in zebrafish and embryonic stem cells. Proceedings of the National Academy of Sciences of the United States of America 2007;104:9685-90.

[19] Ding S, Schultz PG. A role for chemistry in stem cell biology. Nature biotechnology 2004;22:833-40.

[20] Borowiak M, Maehr R, Chen S, Chen AE, Tang W, Fox JL, et al. Small molecules efficiently direct endodermal differentiation of mouse and human embryonic stem cells. Cell stem cell 2009;4:348-58.

[21] Vunjak-Novakovic G, Scadden DT. Biomimetic platforms for human stem cell research. Cell stem cell 2011;8:252-61.

[22] Chai C, Leong KW. Biomaterials approach to expand and direct differentiation of stem cells. Molecular therapy : the journal of the American Society of Gene Therapy 2007;15:467-80.

[23] Trappmann B, Gautrot JE, Connelly JT, Strange DG, Li Y, Oyen ML, et al. Extracellularmatrix tethering regulates stem-cell fate. Nature materials 2012;11:642-9.

[24] Wen JH, Vincent LG, Fuhrmann A, Choi YS, Hribar KC, Taylor-Weiner H, et al. Interplay of matrix stiffness and protein tethering in stem cell differentiation. Nature materials 2014;13:979-

87.

[25] Efe JA, Ding S. The evolving biology of small molecules: controlling cell fate and identity. Philosophical transactions of the Royal Society of London Series B, Biological sciences 2011;366:2208-21.

[26] Li W, Jiang K, Ding S. Concise review: A chemical approach to control cell fate and function. Stem Cells 2012;30:61-8.

[27] Khalil AS, Xie AW, Murphy WL. Context clues: the importance of stem cell-material interactions. ACS chemical biology 2014;9:45-56.

[28] Kong HJ, Boontheekul T, Mooney DJ. Quantifying the relation between adhesion ligandreceptor bond formation and cell phenotype. Proceedings of the National Academy of Sciences of the United States of America 2006;103:18534-9.

[29] LaNasa SM, Bryant SJ. Influence of ECM proteins and their analogs on cells cultured on 2$D$ hydrogels for cardiac muscle tissue engineering. Acta biomaterialia 2009;5:2929-38.

[30] Lutolf MP, Hubbell JA. Synthetic biomaterials as instructive extracellular microenvironments for morphogenesis in tissue engineering. Nature biotechnology 2005;23:47-55.

[31] Shachar M, Tsur-Gang O, Dvir T, Leor J, Cohen S. The effect of immobilized RGD peptide in alginate scaffolds on cardiac tissue engineering. Acta biomaterialia 2011;7:152-62.

[32] Tugulu S, Silacci P, Stergiopulos N, Klok HA. RGD-Functionalized polymer brushes as substrates for the integrin specific adhesion of human umbilical vein endothelial cells. Biomaterials 2007;28:2536-46.

[33] Sapir Y, Kryukov O, Cohen S. Integration of multiple cell-matrix interactions into alginate scaffolds for promoting cardiac tissue regeneration. Biomaterials 2011;32:1838-47. 
[34] Klim JR, Li L, Wrighton PJ, Piekarczyk MS, Kiessling LL. A defined glycosaminoglycanbinding substratum for human pluripotent stem cells. Nature methods 2010;7:989-94.

[35] Walters NJ, Gentleman E. Evolving insights in cell-matrix interactions: elucidating how nonsoluble properties of the extracellular niche direct stem cell fate. Acta biomaterialia 2015;11:3-

16.

[36] Chen W, Shao Y, Li X, Zhao G, Fu J. Nanotopographical Surfaces for Stem Cell Fate Control: Engineering Mechanobiology from the Bottom. Nano today 2014;9:759-84.

[37] Nikkhah M, Edalat F, Manoucheri S, Khademhosseini A. Engineering microscale topographies to control the cell-substrate interface. Biomaterials 2012;33:5230-46.

[38] Riveline D, Zamir E, Balaban NQ, Schwarz US, Ishizaki T, Narumiya S, et al. Focal contacts as mechanosensors: externally applied local mechanical force induces growth of focal contacts by an mDia1-dependent and ROCK-independent mechanism. The Journal of cell biology 2001;153:1175-86.

[39] Dalby MJ, Gadegaard N, Oreffo RO. Harnessing nanotopography and integrin-matrix interactions to influence stem cell fate. Nature materials 2014;13:558-69.

[40] Discher DE, Janmey P, Wang YL. Tissue cells feel and respond to the stiffness of their substrate. Science 2005;310:1139-43.

[41] Kilian KA, Bugarija B, Lahn BT, Mrksich M. Geometric cues for directing the differentiation of mesenchymal stem cells. Proceedings of the National Academy of Sciences of the United States of America 2010;107:4872-7.

[42] Bhana B, Iyer RK, Chen WL, Zhao R, Sider KL, Likhitpanichkul M, et al. Influence of substrate stiffness on the phenotype of heart cells. Biotechnology and bioengineering 2010;105:1148-60.

[43] McBeath R, Pirone DM, Nelson CM, Bhadriraju K, Chen CS. Cell shape, cytoskeletal tension, and RhoA regulate stem cell lineage commitment. Developmental cell 2004;6:483-95. [44] Anderson DG, Levenberg S, Langer R. Nanoliter-scale synthesis of arrayed biomaterials and application to human embryonic stem cells. Nature biotechnology 2004;22:863-6. [45] Lutolf MP, Gilbert PM, Blau HM. Designing materials to direct stem-cell fate. Nature 2009;462:433-41.

[46] Yang F, Mei Y, Langer R, Anderson DG. High throughput optimization of stem cell microenvironments. Combinatorial chemistry \& high throughput screening 2009;12:554-61.

[47] Mei Y, Elliott JT, Smith JR, Langenbach KJ, Wu T, Xu C, et al. Gradient substrate assembly for quantifying cellular response to biomaterials. Journal of biomedical materials research Part $A$ 2006;79:974-88.

[48] Mei Y, Wu T, Xu C, Langenbach KJ, Elliott JT, Vogt BD, et al. Tuning cell adhesion on gradient poly(2-hydroxyethyl methacrylate)-grafted surfaces. Langmuir : the ACS journal of surfaces and colloids 2005;21:12309-14.

[49] Mei Y. Microarrayed Materials for Stem Cells. Materials today 2012;15.

[50] Anderson DG, Putnam D, Lavik EB, Mahmood TA, Langer R. Biomaterial microarrays: rapid, microscale screening of polymer-cell interaction. Biomaterials 2005;26:4892-7.

[51] Mei Y, Saha K, Bogatyrev SR, Yang J, Hook AL, Kalcioglu ZI, et al. Combinatorial development of biomaterials for clonal growth of human pluripotent stem cells. Nature materials 2010;9:768-78.

[52] Wrighton PJ, Klim JR, Hernandez BA, Koonce CH, Kamp TJ, Kiessling LL. Signals from the surface modulate differentiation of human pluripotent stem cells through glycosaminoglycans and integrins. Proceedings of the National Academy of Sciences of the United States of America 2014;111:18126-31.

[53] Nguyen EH, Zanotelli MR, Schwartz MP, Murphy WL. Differential effects of cell adhesion, modulus and VEGFR-2 inhibition on capillary network formation in synthetic hydrogel arrays. Biomaterials 2014;35:2149-61. 
[54] Saha K, Mei Y, Reisterer CM, Pyzocha NK, Yang J, Muffat J, et al. Surface-engineered substrates for improved human pluripotent stem cell culture under fully defined conditions. Proceedings of the National Academy of Sciences of the United States of America 2011;108:18714-9.

[55] Celiz AD, Smith JG, Patel AK, Langer R, Anderson DG, Barrett DA, et al. Chemically diverse polymer microarrays and high throughput surface characterisation: a method for discovery of materials for stem cell culturedaggerElectronic supplementary information (ESI) available. See DOI: 10.1039/c4bm00054dClick here for additional data file. Biomaterials science 2014;2:1604-11.

[56] Zhang R, Mjoseng HK, Hoeve MA, Bauer NG, Pells S, Besseling R, et al. A thermoresponsive and chemically defined hydrogel for long-term culture of human embryonic stem cells. Nature communications 2013;4:1335.

[57] Celiz AD, Harrington HC, Hook A. High throughput assessment and chemometric analysis of theinteraction of epithelial and fibroblast cells with a polymer library. Applied Surface Science 2014:926-35.

[58] Hay DC, Pernagallo S, Diaz-Mochon JJ, Medine CN, Greenhough S, Hannoun Z, et al. Unbiased screening of polymer libraries to define novel substrates for functional hepatocytes with inducible drug metabolism. Stem cell research 2011;6:92-102.

[59] MacBeath G, Schreiber SL. Printing proteins as microarrays for high-throughput function determination. Science 2000;289:1760-3.

[60] Flaim CJ, Chien S, Bhatia SN. An extracellular matrix microarray for probing cellular differentiation. Nature methods 2005;2:119-25.

[61] Flaim CJ, Teng D, Chien S, Bhatia SN. Combinatorial signaling microenvironments for studying stem cell fate. Stem cells and development 2008;17:29-39.

[62] Soen Y, Mori A, Palmer TD, Brown PO. Exploring the regulation of human neural precursor cell differentiation using arrays of signaling microenvironments. Molecular systems biology 2006;2:37.

[63] Brafman DA, Chien S, Willert K. Arrayed cellular microenvironments for identifying culture and differentiation conditions for stem, primary and rare cell populations. Nature protocols 2012;7:703-17.

[64] Dolatshahi-Pirouz A, Nikkhah M, Gaharwar AK, Hashmi B, Guermani E, Aliabadi H, et al. A combinatorial cell-laden gel microarray for inducing osteogenic differentiation of human mesenchymal stem cells. Scientific reports 2014;4:3896.

[65] Rasi Ghaemi S, Harding F, Delalat B, Vasani R, Voelcker NH. Surface engineering for longterm culturing of mesenchymal stem cell microarrays. Biomacromolecules 2013;14:2675-83.

[66] Giam LR, Massich MD, Hao L, Shin Wong L, Mader CC, Mirkin CA. Scanning probeenabled nanocombinatorics define the relationship between fibronectin feature size and stem cell fate. Proceedings of the National Academy of Sciences of the United States of America 2012;109:4377-82.

[67] Derda R, Li L, Orner BP, Lewis RL, Thomson JA, Kiessling LL. Defined substrates for human embryonic stem cell growth identified from surface arrays. ACS chemical biology 2007;2:347-55.

[68] Derda R, Musah S, Orner BP, Klim JR, Li L, Kiessling LL. High-throughput discovery of synthetic surfaces that support proliferation of pluripotent cells. Journal of the American Chemical Society 2010;132:1289-95.

[69] Koepsel JT, Brown PT, Loveland SG, Li WJ, Murphy WL. Combinatorial screening of chemically defined human mesenchymal stem cell culture substrates. Journal of materials chemistry 2012;22:19474-81.

[70] Zhang D, Kilian KA. Peptide microarrays for the discovery of bioactive surfaces that guide cellular processes: a single step azide-alkyne "click" chemistry approach. J Mater Chem B 2014;2:4280. 
[71] Benoit DS, Schwartz MP, Durney AR, Anseth KS. Small functional groups for controlled differentiation of hydrogel-encapsulated human mesenchymal stem cells. Nature materials 2008;7:816-23.

[72] McNamara LE, Sjostrom T, Seunarine K, Meek RD, Su B, Dalby MJ. Investigation of the limits of nanoscale filopodial interactions. Journal of tissue engineering 2014;5:2041731414536177.

[73] Dalby MJ, Gadegaard N, Tare R, Andar A, Riehle MO, Herzyk P, et al. The control of human mesenchymal cell differentiation using nanoscale symmetry and disorder. Nature materials 2007;6:997-1003.

[74] McMurray RJ, Gadegaard N, Tsimbouri PM, Burgess KV, McNamara LE, Tare R, et al. Nanoscale surfaces for the long-term maintenance of mesenchymal stem cell phenotype and multipotency. Nature materials 2011;10:637-44.

[75] Tsimbouri PM, McMurray RJ, Burgess KV, Alakpa EV, Reynolds PM, Murawski K, et al. Using nanotopography and metabolomics to identify biochemical effectors of multipotency. ACS nano 2012;6:10239-49.

[76] Chen W, Villa-Diaz LG, Sun Y, Weng S, Kim JK, Lam RH, et al. Nanotopography influences adhesion, spreading, and self-renewal of human embryonic stem cells. ACS nano 2012;6:4094103.

[77] Khademhosseini A, Langer R, Borenstein J, Vacanti JP. Microscale technologies for tissue engineering and biology. Proceedings of the National Academy of Sciences of the United States of America 2006;103:2480-7.

[78] Unadkat HV, Hulsman M, Cornelissen K, Papenburg BJ, Truckenmuller RK, Carpenter AE, et al. An algorithm-based topographical biomaterials library to instruct cell fate. Proceedings of the National Academy of Sciences of the United States of America 2011;108:16565-70.

[79] Unadkat HV, Rewagad RR, Hulsman M, Hulshof GF, Truckenmuller RK, Stamatialis DF, et al. A modular versatile chip carrier for high-throughput screening of cell-biomaterial interactions. Journal of the Royal Society, Interface / the Royal Society 2013;10:20120753.

[80] Hoffman BD, Grashoff C, Schwartz MA. Dynamic molecular processes mediate cellular mechanotransduction. Nature 2011;475:316-23.

[81] Swift J, Ivanovska IL, Buxboim A, Harada T, Dingal PC, Pinter J, et al. Nuclear lamin-A scales with tissue stiffness and enhances matrix-directed differentiation. Science 2013;341:1240104.

[82] Engler AJ, Sen S, Sweeney HL, Discher DE. Matrix elasticity directs stem cell lineage specification. Cell 2006;126:677-89.

[83] Musah S, Wrighton PJ, Zaltsman Y, Zhong X, Zorn S, Parlato MB, et al. Substratuminduced differentiation of human pluripotent stem cells reveals the coactivator YAP is a potent regulator of neuronal specification. Proceedings of the National Academy of Sciences of the United States of America 2014;111:13805-10.

[84] Scadden DT. The stem-cell niche as an entity of action. Nature 2006;441:1075-9.

[85] Gilbert PM, Havenstrite KL, Magnusson KE, Sacco A, Leonardi NA, Kraft P, et al. Substrate elasticity regulates skeletal muscle stem cell self-renewal in culture. Science 2010;329:1078-81. [86] Cosgrove BD, Gilbert PM, Porpiglia E, Mourkioti F, Lee SP, Corbel SY, et al. Rejuvenation of the muscle stem cell population restores strength to injured aged muscles. Nature medicine 2014;20:255-64.

[87] Gobaa S, Hoehnel S, Roccio M, Negro A, Kobel S, Lutolf MP. Artificial niche microarrays for probing single stem cell fate in high throughput. Nature methods 2011;8:949-55.

[88] Woodruff K, Fidalgo LM, Gobaa S, Lutolf MP, Maerkl SJ. Live mammalian cell arrays. Nature methods 2013;10:550-2.

[89] Lee J, Abdeen AA, Zhang D, Kilian KA. Directing stem cell fate on hydrogel substrates by controlling cell geometry, matrix mechanics and adhesion ligand composition. Biomaterials 2013;34:8140-8. 
[90] Weng S, Fu J. Synergistic regulation of cell function by matrix rigidity and adhesive pattern. Biomaterials 2011;32:9584-93.

[91] Ranga A, Gobaa S, Okawa Y, Mosiewicz K, Negro A, Lutolf MP. 3D niche microarrays for systems-level analyses of cell fate. Nature communications 2014;5:4324.

[92] Mosiewicz KA, Kolb L, van der Vlies AJ, Martino MM, Lienemann PS, Hubbell JA, et al. In situ cell manipulation through enzymatic hydrogel photopatterning. Nature materials 2013;12:1072-8.

[93] Wilson MJ, Jiang Y, Yanez-Soto B, Liliensiek S, Murphy WL, Nealey PF. Arrays of topographically and peptide-functionalized hydrogels for analysis of biomimetic extracellular matrix properties. Journal of vacuum science and technology B, Nanotechnology \& microelectronics : materials, processing, measurement, \& phenomena : JVST B 2012;30:6F903. [94] Osafune K, Caron L, Borowiak M, Martinez RJ, Fitz-Gerald CS, Sato Y, et al. Marked differences in differentiation propensity among human embryonic stem cell lines. Nature biotechnology 2008;26:313-5.

[95] Hu BY, Weick JP, Yu J, Ma LX, Zhang XQ, Thomson JA, et al. Neural differentiation of human induced pluripotent stem cells follows developmental principles but with variable potency. Proceedings of the National Academy of Sciences of the United States of America 2010;107:4335-40.

[96] Lee CH, Rodeo SA, Fortier LA, Lu C, Erisken C, Mao JJ. Protein-releasing polymeric scaffolds induce fibrochondrocytic differentiation of endogenous cells for knee meniscus regeneration in sheep. Science translational medicine 2014;6:266ra171.

[97] Lee CH, Cook JL, Mendelson A, Moioli EK, Yao H, Mao JJ. Regeneration of the articular surface of the rabbit synovial joint by cell homing: a proof of concept study. Lancet 2010;376:440-8.

[98] Ye L, Chang YH, Xiong Q, Zhang P, Zhang L, Somasundaram P, et al. Cardiac repair in a porcine model of acute myocardial infarction with human induced pluripotent stem cell-derived cardiovascular cells. Cell stem cell 2014;15:750-61.

[99] Chong JJ, Yang X, Don CW, Minami E, Liu YW, Weyers JJ, et al. Human embryonic-stemcell-derived cardiomyocytes regenerate non-human primate hearts. Nature 2014.

[100] Ranga A, Lutolf MP. High-throughput approaches for the analysis of extrinsic regulators of stem cell fate. Current opinion in cell biology 2012;24:236-44.

[101] DeForest CA, Anseth KS. Advances in bioactive hydrogels to probe and direct cell fate. Annual review of chemical and biomolecular engineering 2012;3:421-44.

\section{Figure 1.}

Stem cell interactions with chemical and physical cues. (a) Chemical interactions on materials can regulate growth factor signaling. Engineered materials may incorporate (i) covalently bound glycosaminoglycans (GAGs) or proteoglycans (PGs) or (ii) moieties that bind GAGs/PGs, which can in turn sequester growth factors from the stem cell microenvironment. Alternatively, materials may be functionalized with (iii) moieties that bind growth factors or (iv) moieties that directly interact with growth factor receptors (GFRs), to upregulate or downregulate GFR signaling. Finally, GFRs and their associated signaling pathways may synergize with (v) integrin-mediated adhesion and signaling downstream of adhesion. (b) Mechanical properties of the microenvironment. Resistance to deformation on stiff materials increases cytoskeletal tension of human mesenchymal stem cells (hMSC) through focal adhesion kinase (FAK) and Rho-associated kinase (ROCK) activity, leading to differentiation. (left) Introduction of topography results in rearrangement of integrins at the cell-material interface, promoting 
topography-dependent hMSC proliferation, self-renewal, or differentiation. (right) (Figure from reference [27] with permission).

\section{Figure 2.}

High-throughput screening of biomaterials for clonal growth. (a) Monomers used for array synthesis were classified into two categories: "major" monomers that constitute $>50 \%$ of the reactant mixture and "minor" monomers that constitute $<50 \%$ of the mixture. Sixteen major monomers were named numerically (blue), and six minor monomers were labeled alphabetically (orange). (b) Schematic diagram of the screen. First, transgenic Oct4-GFP hES cells were maintained on mEFs. Then flow cytometry enabled the isolation of high purity undifferentiated hES cells from the completely dissociated coculture of hES cells and mEFs. A flow cytometry histogram during a representative cell sort is shown. GFP+ cells (right of the black gate) were seeded onto the arrays, whereas the differentiated cells and mEFs (GFP-, left of the black gate) were not used. A photograph of the polymer microarray with 16 polymer spots is shown to illustrate dimensions and separation. Each polymer was also characterized using highthroughput methods to characterize its surface roughness, indentation elastic modulus, wettability (water contact angle, ${ }^{\circ} \mathrm{C}$ ) and surface chemistry. Finally, the cellular response on the polymer array was quantified using laser-scanning cytometry, and structure-function relationships were determined by numerical analysis of both the cellular response and materials characterization data. (Figure from reference [51] with permission).

\section{Figure 3.}

SAM surface array screen for ES cell growth and self-renewal. (a) Structure of alkanethiols used for the assembly of the array. "R" denotes amino acid side chains. (b) A two-step process was used to generate the arrays. A uniform SAM composed of perfluoro-AT was photopatterned and solutions of peptide-ATs were spotted onto the exposed gold areas to form peptide-terminated SAM array elements. (c) A representative array containing 18 different peptide-ATs was screened to identify surfaces that promote proliferation of ES cell line H9. The peptidedisplaying SAMs are arranged in a mirror-symmetric pattern (bottom and top halves of chip have identical array elements). Each half of the array contains 18 laminin-derived peptide-ATs spotted in groups of four ( $2 \times 2$ elements) arranged in a left-to-right horizontal comb pattern. The remaining array elements are filled with nonadhesive glucamine-AT. The array was incubated with media containing $20 \%$ FBS and thoroughly washed with serum-free media. Cells were grown on the array for $6 \mathrm{~d}$ in culture media, fixed, and stained for alkaline phosphatase (AP). The positions of cell growth are symmetric and emphasize the reproducibility of ES cell responses to the array elements. The array was mounted onto a glass slide and scanned using a flatbed scanner. The phase-contrast $10 \mathrm{x}$ images reveal morphological differences between AP-positive undifferentiated (left) and AP-negative differentiated ES cells (right). Array dimensions: $22 \times 22 \mathrm{~mm}$; each element is $0.8 \mathrm{~mm}$. (d) Summary of results from multiple screens for 18 laminin-derived peptides and ES cell lines $\mathrm{H1}$ and H9. Laminin chain origin is shown for each peptide. Following 5-7 d of growth, substrates were categorized according to their ability to accommodate confluent (square-shaped) and undifferentiated colonies, as judged by staining for alkaline phosphatase (purple) or Oct4 (green). Each synthetic substrate was tested four to eight times in each screen; therefore, the fraction of array elements presenting square ES cell 
colonies serves as a convenient measure of substrate efficiency. Representative results for one peptide in each category are shown, and the corresponding peptide sequences are underlined. The apparent higher intensity of Oct4 around the edges of the array element can be attributed to differences in thicknesses of ES cell colony around the edges or differentiation of overcrowded cells in the middle of the array element. The latter is not observed when cells are cultured on large area substrates that do not restrict colony growth. (Figure from reference [54] with permission).

\section{Figure 4.}

Molecules included in PEG hydrogels. (a) The hydrogels are composed of (i) 8-arm PEG molecules, with each arm functionalized with a norbornene molecule; (ii) Di-thiolated PEG crosslinking molecules bridge multiple 8-arm PEG molecules together into an ordered polymer network. A di-thiolated PEG molecule acts as an inert crosslinking molecule that is not celldegradable; (iii) In bioactive hydrogels, PEG molecules are decorated with CRGDS adhesion peptide or CRDGS scrambled peptide to modulate cell adhesion to the hydrogel; (iv) Dithiolated matrix metalloproteinase (MMP) labile crosslinking peptides enable cell-driven hydrogel degradation. (b) "Background" hydrogels are void of cell adhesion molecules and are not subject to cell-driven degradation (top). "Hydrogel spots" modulate cell behavior through covalently attached adhesion molecules and are biodegradable via MMP activity (bottom). (c) Schematic representation of hydrogel array fabrication. (1) Separate hydrogel spot solutions containing various ratios of CRGDS adhesion peptide (Red circles) and a scrambled CRDGS non-functional peptide (Blue circles) are pipetted into wells of a PDMS stencil. Total pendant peptide concentration is fixed at $2 \mathrm{mM}$ in all solutions. (2) The hydrogel spots are crosslinked in the stencil using UV light. (3) A crosslinked 1-mm thick "background" hydrogel slab is laid on top of the crosslinked bioactive hydrogel spots. A thin layer of background hydrogel solution is added to the slab to anchor the cured spots to the background. (4) The hydrogel spots are anchored to the background after treatment with UV light. (5) The completed hydrogel array is removed from the stencil. Red boxes highlight the raised spots in the schematic and side view images of the arrays. (Figure from reference [71] with permission.)

\section{Figure 5.}

Nanoscale disorder and adhesion bridging. (a) Electron-beam lithography was used to demonstrate that neither order nor randomness successfully led to osteoinduction of MSCs. SQ, square (within the square array the individual pits are $120 \mathrm{~nm}$ in diameter, 100-nm deep and have a 300-nm center-center spacing); RAND, random. However, controlled disorder (NSQ20 and NSQ50, same as SQ but with $\pm 20 \mathrm{~nm}$ and $\pm 50 \mathrm{~nm}$ offset from the $300 \mathrm{~nm}$ center-center position) produced abundant, spontaneous, osteogenesis in basal media. Cells are shown in red (actin) and osteogenesis is shown in green (osteopontin). (b) At the adhesion level, adding a level of disorder to RGDs placed $70 \mathrm{~nm}$ apart allowed much greater integrin clustering in MSCs. Bottom panels show an ordered lattice (right) with RGDs placed $>70 \mathrm{~nm}$ apart with little integrin clustering possible (open circles). However, if a level of disorder (left) is added while there are areas with gaps where adhesion does not occur, more RGDs are moved within gathering distance (closed circles). (c,d) Fluorescence microscopy images showing 800-nm-diameter fibronectin circles (red, c) and 200-nm-diameter vitronectin circles (red, d) with adhesions 
(vinculin in green) seen bridging between the circles (arrows). (Figure from reference [39] with permission)

\section{Figure 6.}

TopoChip design. (a) A schematic representation of a sequence of events that is proposed to be followed for high-throughput screening of biomedical materials starting from initial design to clinical application. (b) Design of the TopoChip is based on the use of primitives. Three types of primitives, namely circles, triangles, and lines were used to construct features. Repeated features constitute a TopoUnit and two times 2,176 = 4,352 TopoUnits constitute a TopoChip (size ranges are indicated). In addition, four flat control surfaces are included. (c) TopoChip is divided into four quadrants. TopoUnits in quadrant A are repeated in quadrant Ai and similarly TopoUnits in quadrant $B$ are repeated in quadrant $\mathrm{Bi}$ in order to exclude site specific or localized effects. (d-g) SEM images of cells showing diverse cellular morphologies. Scale bar, $90 \mu \mathrm{m}$. (Figure from reference [78] with permission)

\section{Figure 7.}

Pliant hydrogel promotes MuSC survival and prevents differentiation in culture. (a) PEG hydrogels with tunable mechanical properties. Young's modulus $(E)$ is linearly correlated with precursor polymer concentration $(n=4)$; red circle indicates muscle elasticity. (b) Image of a pliant PEG hydrogel on a green spatula. Scale bar, $7 \mathrm{~mm}$ (top). Confocal immunofluorescence image of hydrogel microcontact printed with laminin specifically at the bottom of hydrogel microwells (i.e., from the "tips" of the micropillars). Scale bar, $125 \mathrm{~mm}$ (bottom). (c) Dissected tibialis anterior muscles ( $n=5$ mice, 10 muscles total) were analyzed by rheometry (horizontal line indicates the mean). (Figure from reference [85] with permission)

\section{Figure 8.}

3D combinatorial screening from a modular materials library. (a) Enzymatically mediated crosslinking scheme, where $x x x x$ xxxx represents specific peptide sequence. (b) Components of the combinatorial toolbox are assembled from biologically relevant factors in categorized form. Stiffness and MMP sensitivity of the matrix are set within the experimentally measured ranges shown ( $n=3$ replicates). (c) Experimental process consists of combining the components library with reporter cells using robotic mixing and dispensing technology into 1,536 -well plates ( $n=3$ replicates). ( $d-f)$ Automated microscopy and image processing to determine colony size and GFP intensity. Average cell density per well is set by the initial cell concentration used in the experiment, and exact initial cell density for each well is determined retrospectively by imaging. Examples of a set of images tracking colony growth in a single well over the course of a 5-day experiment (d) 3D confocal reconstruction (e) and image segmentation are shown (f). Scale bar, $200 \mathrm{~mm}$. (Figure from reference [91] with permission) 
Figure 1
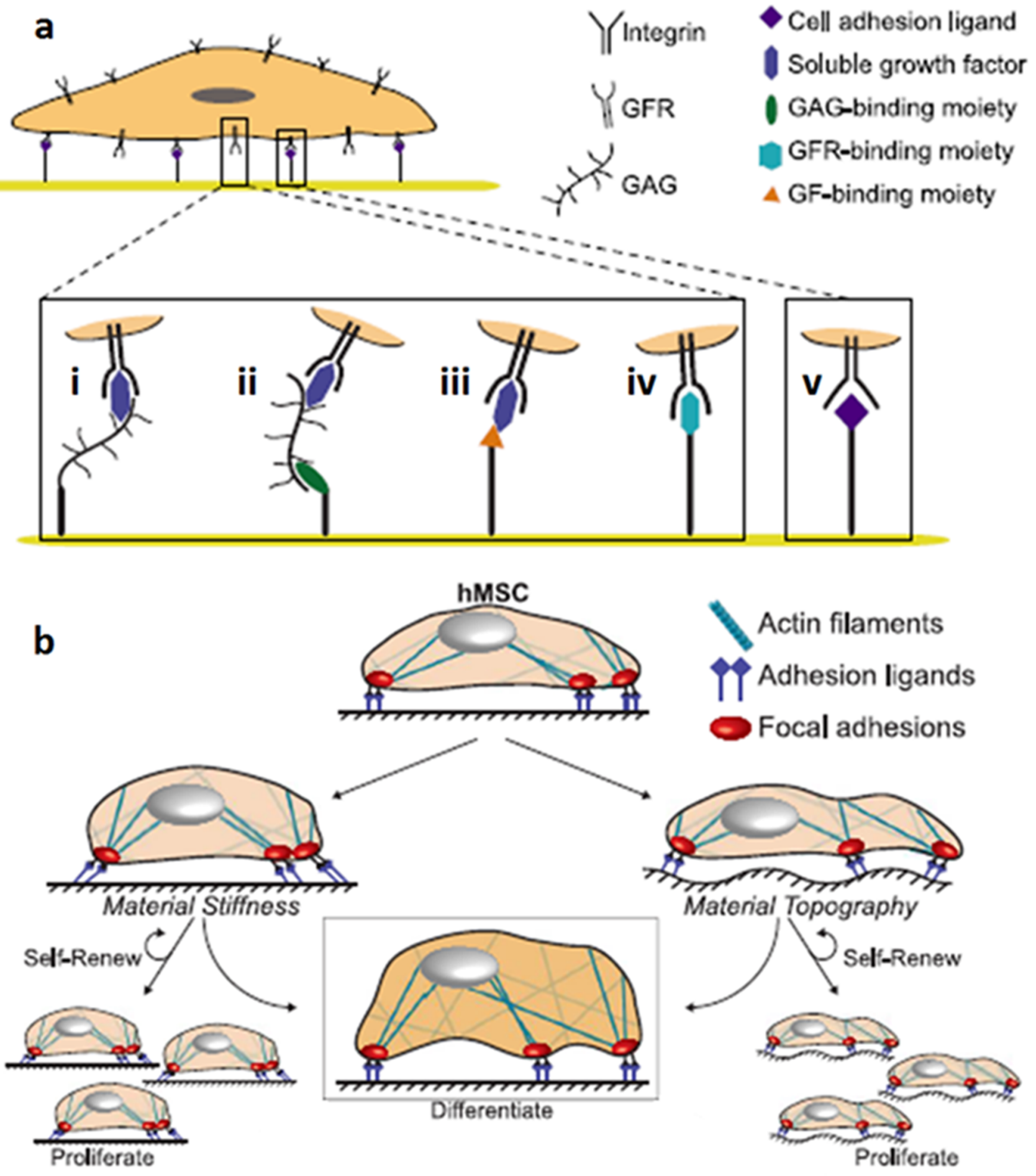


\section{Figure 2}

$$
\text { (16) }
$$

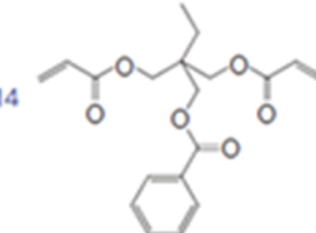

邹

b

OCt4-GFP transgenic hES cells
Single-cell sort transgenic GFP. hES cells

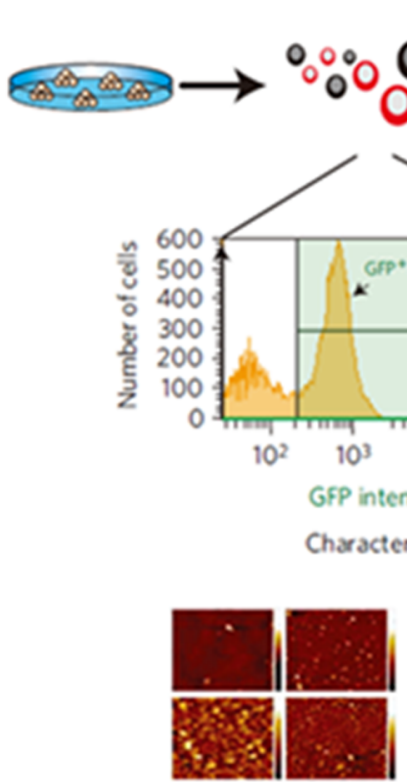

Surface roughness
Seed-sorted cells onto diverse polymer array and culture for 7 days $\Delta h$

Depth Indentation elastic modulus

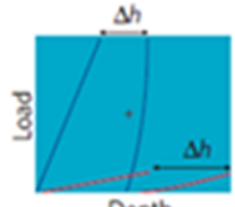

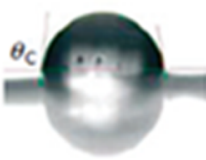

Wettabiisty

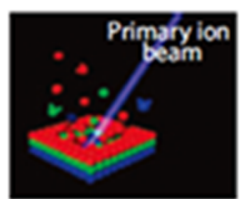

Surface chemistry
Stain for hES cell-colony growth and quantify cellular response by high-content imaging

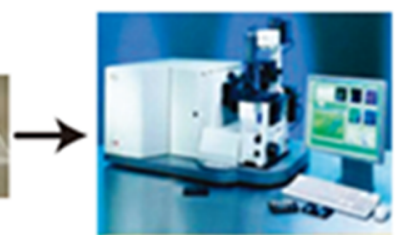

Map out the relationship between hES cell expansion and materials

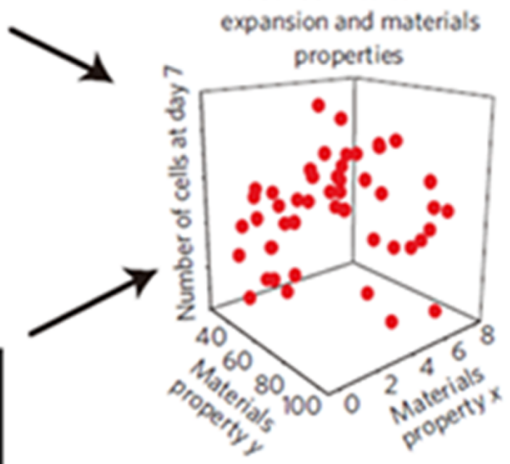


a

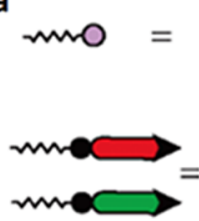

Peptide-AT

b

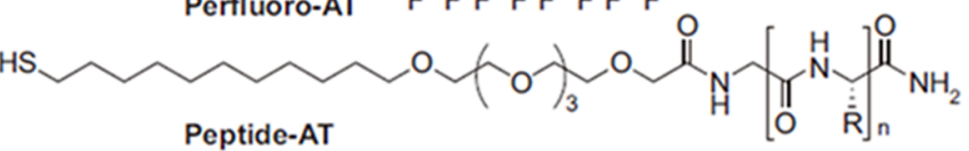<smiles>FC(F)(F)C(F)(F)C(F)(F)C(F)(F)C(F)(F)C(F)(F)C(F)(F)C(F)(F)CCCCCCCCCCCS</smiles>

C

UV-irradiation through

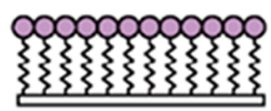
photomask
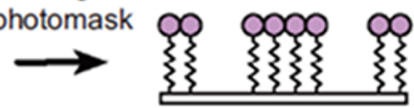

Spotting of peptide-AT
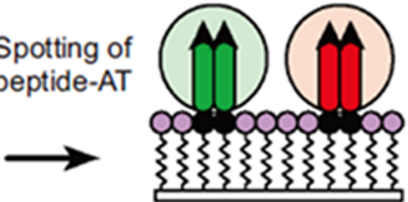

d

Classification with example

Reproducible adhesion/proliferation

(>75\% of the array elements contain confluent ES cell colony in at least 3 screens)

DIRVTLNRL

TTVKYIFR

RNIAEIIKDI

RYWLPR

$\gamma$-Chain

$\gamma$-Chain

$\gamma$-Chain

$\gamma$-Chain

$\beta$-Chain

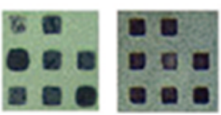

$7 / 8$

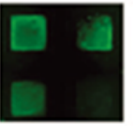

$3 / 4$

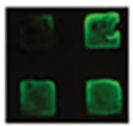

$3 / 4$

\section{RKRLQVQSIRT $\quad \alpha$-Chain \\ TWYKIAFQRNRK $\alpha$-Chain \\ LGTIPG \\ RGSDPK \\ $\beta$-Chain \\ Scrambled control}

$\alpha$-Chain

RGDSPK

ASIKVAVSADR

NRWHSIYITRFG

SLVRNRRVITIQ

SINNNR

PDSGR

SDPGYIGSR

TSIKIRGTYS

DFKLFAVY

$\alpha$-Chain

$\alpha$-Chain

$\alpha$-Chain

$\beta$-Chain

$\beta$-Chain

$\gamma$-Chain

$\gamma$, modified
No adhesion/proliferation

( $>75 \%$ criteria was not met in any of the screens)
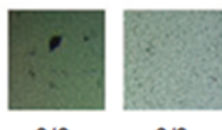

$0 / 8$

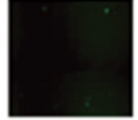

$0 / 4$

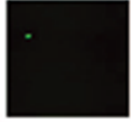

$0 / 4$

Variable adhesion

(intermediate results)

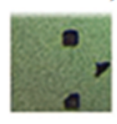

$2 / 8$

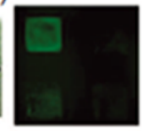

H9 (anti-Oct4)

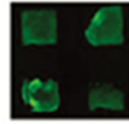

$3 / 4$

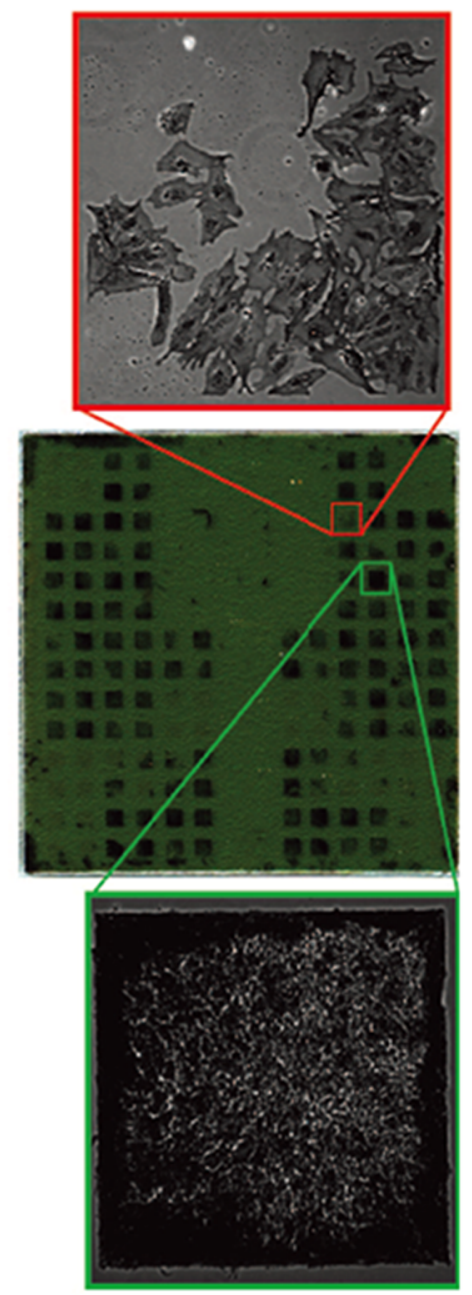


Figure 4

a

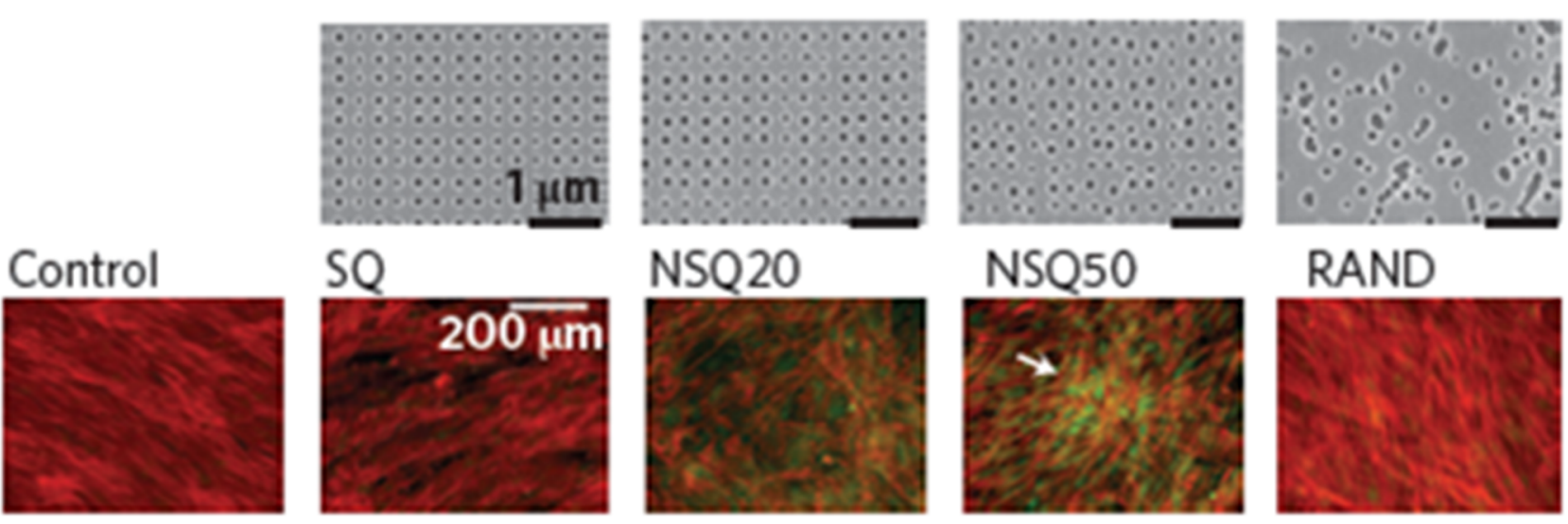

b
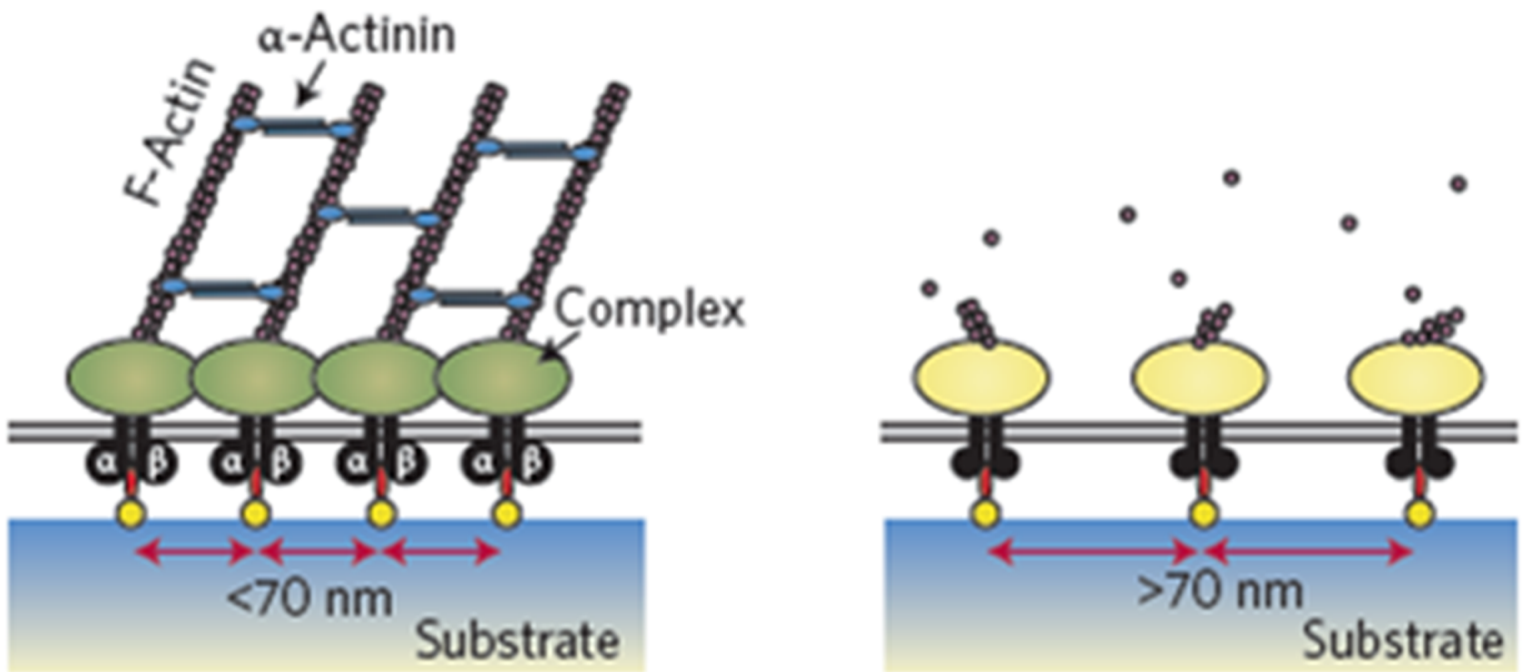

OAunanoparticle ORGD-thiol dbintegrin Cell membrane

Disordered

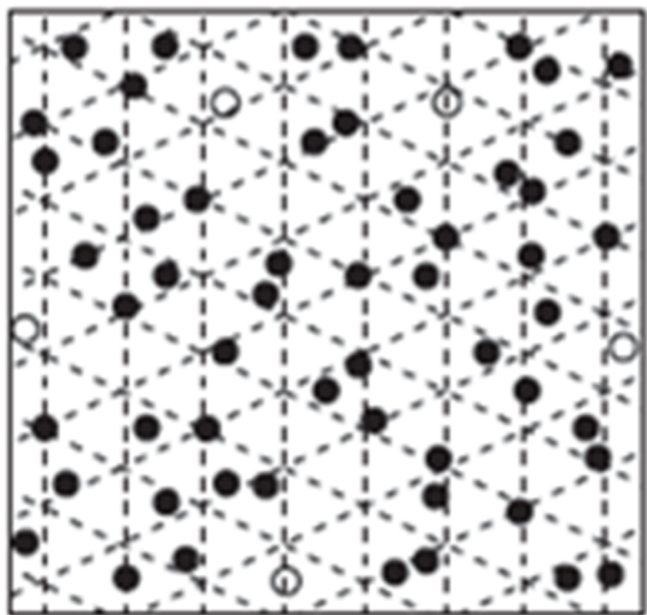

- Clustering integrin
Ordered

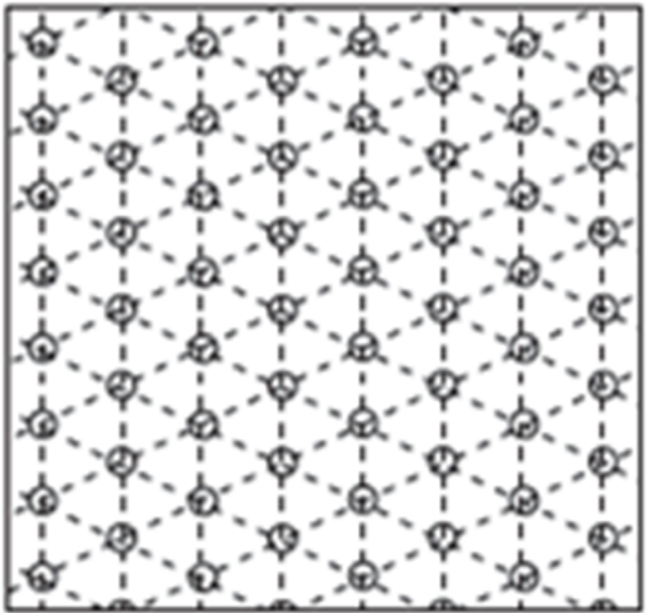

- Non-clustering integrin

d
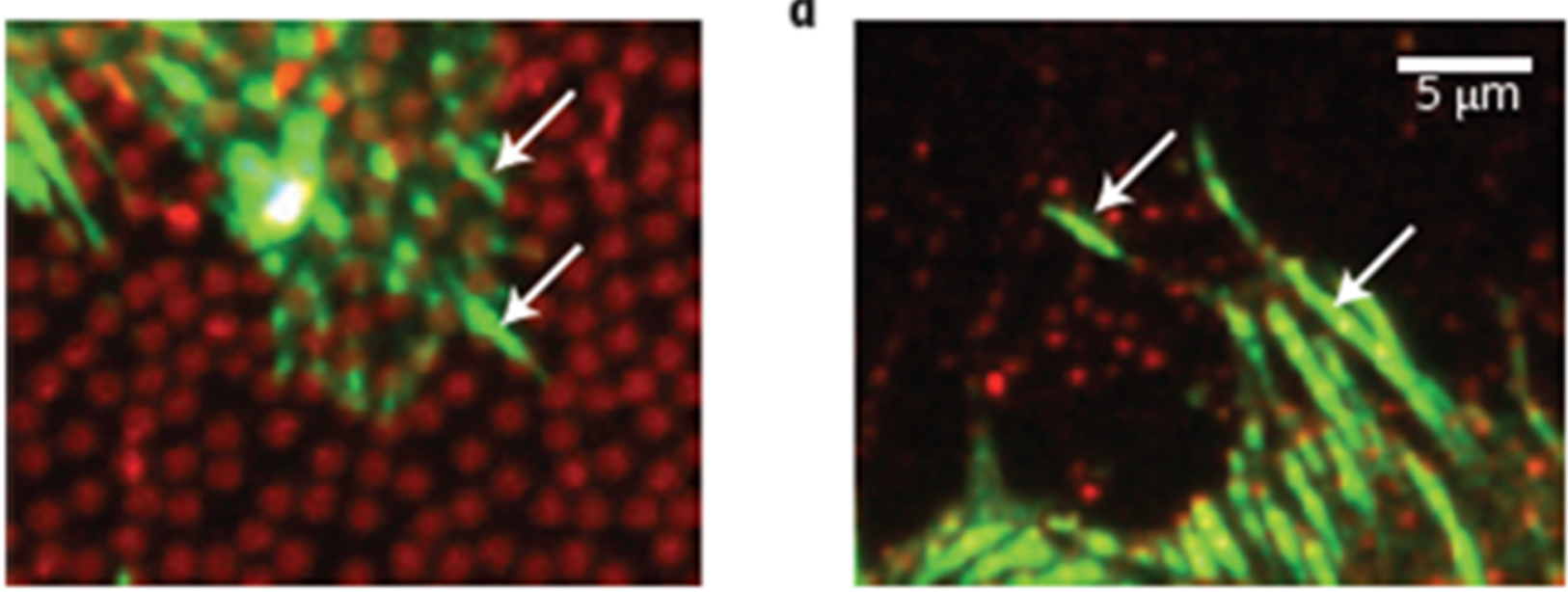
Figure 5

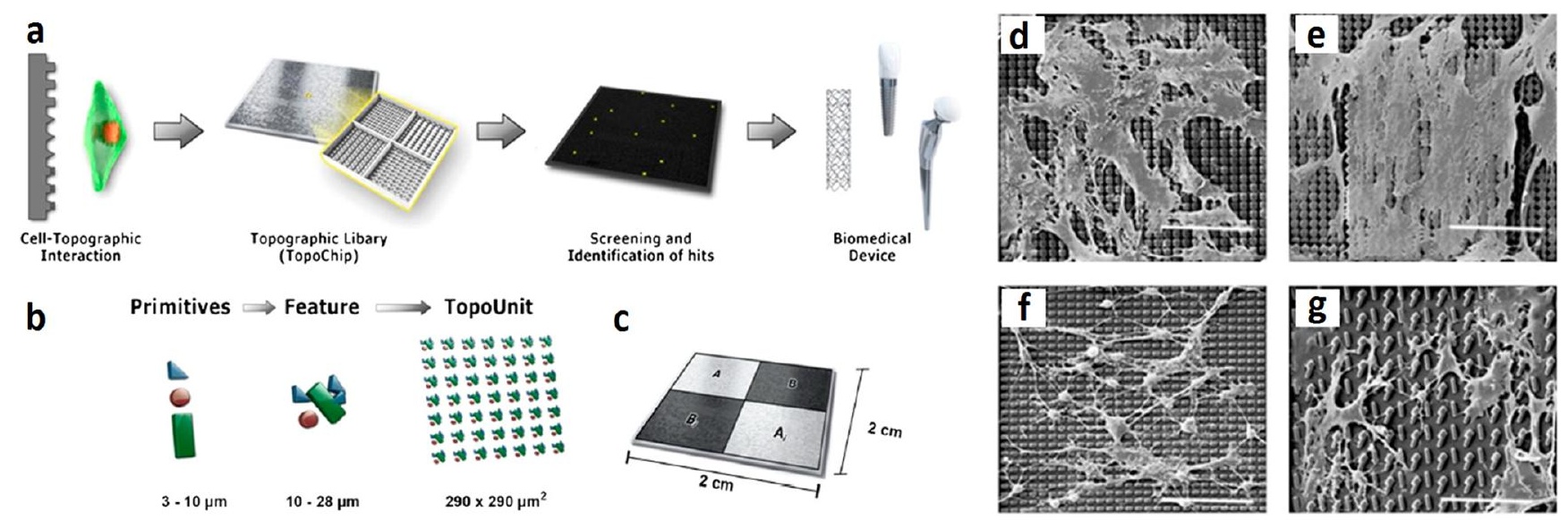


Figure 6
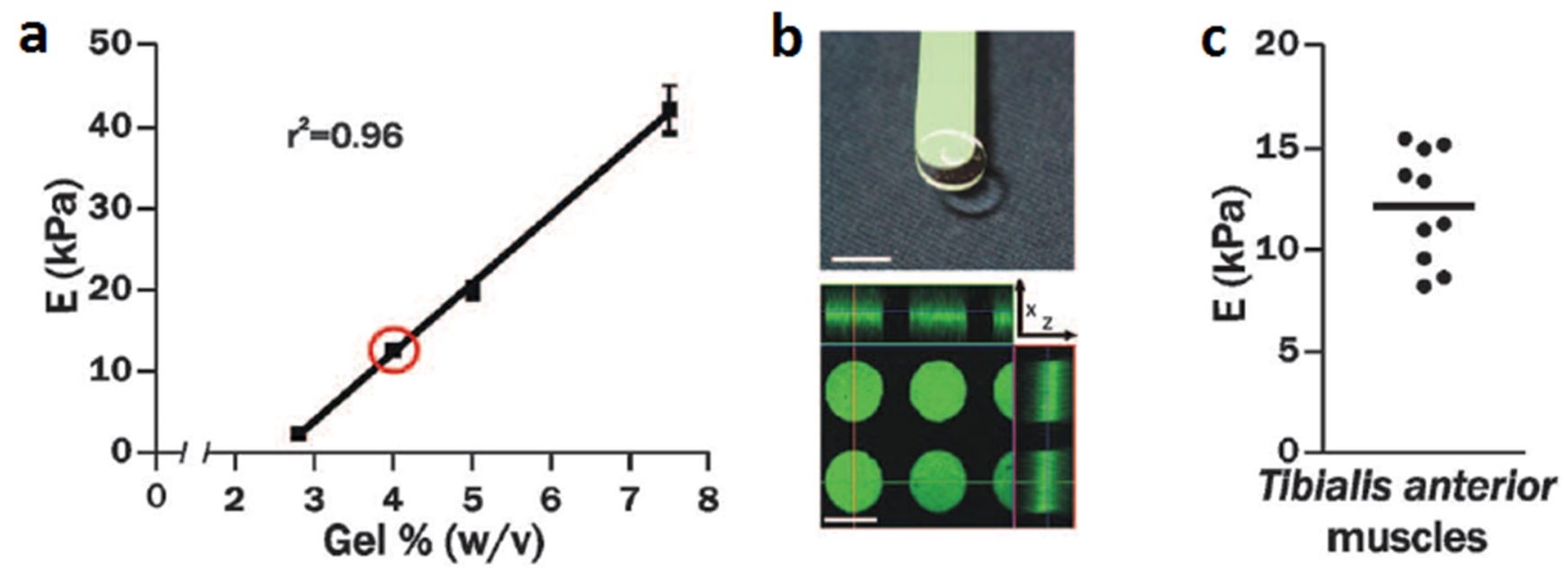


\section{Figure 7}

a
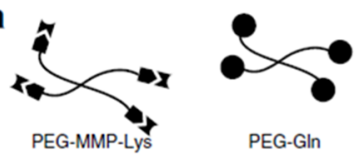

7x:FKGG $x x x x x x x x$ ERCG : NQEQVSPLERCG MMP cleavage site

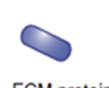

ECM protein

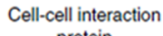
protein

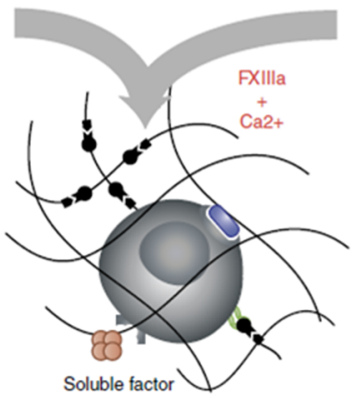

b

Mechanical properties
(MP)

Degradability (DG)

Cell density
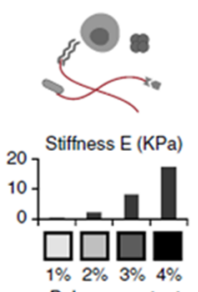

Polymer content

Extracellular matrix components (EM)

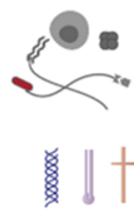

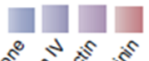

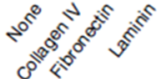

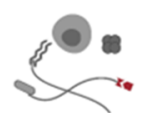

30 MMP sensitivity $(\% / \mathrm{hr})$

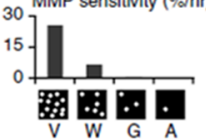

Peptide sequence

Cell-cell interaction

components

(CC)
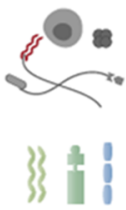

4888

回四四回回回 50.

factors

(SF)

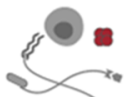

c

Oct4-GFP mESC

Materials Library

MP $\square \square \square \square$

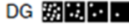

EM 미미미 $\begin{aligned} \bullet \bullet & \text { CC } \\ \square \square & \text { SF }\end{aligned}$
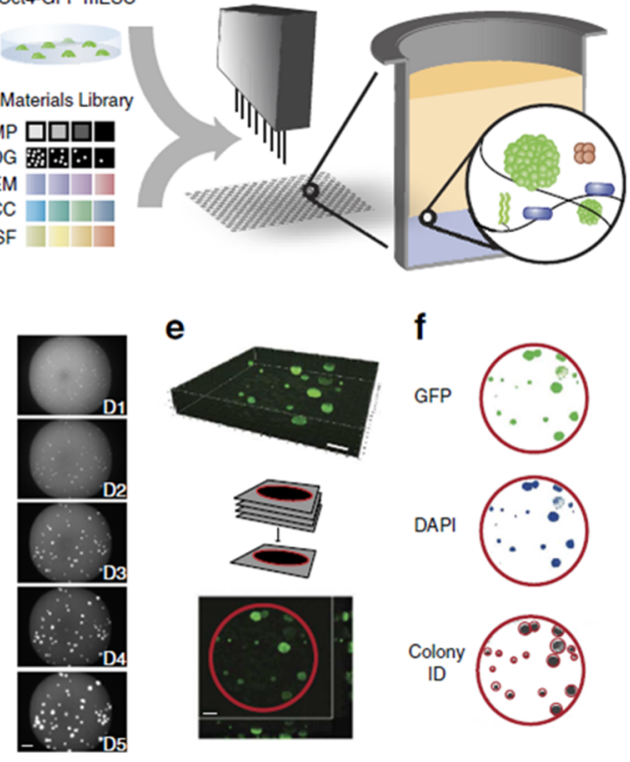

d

e

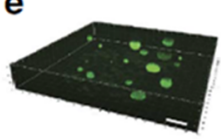

f
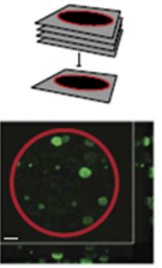

GFP

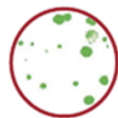

DAP

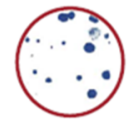

Colony
ID 


\section{Figure 8}

a 8-arm 20-kDa PEG-norbornene

$$
\begin{aligned}
& \text { Aromonizon } \\
& 4 \sum^{\circ} \sum^{\circ} \quad \begin{array}{c}
\text { Schematic } \\
\text { symbol: }
\end{array}
\end{aligned}
$$

Non-degradable
PEG-dithiol
Crosslinker

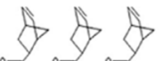

PEG-norbornene

conjugated to $2 x$ CRGDS

$$
\text { A }
$$

$$
\text { C-RGDS }
$$

MMP-labile KCGGPQGIWGQGCK

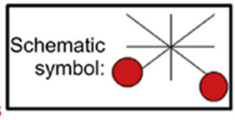

Crosslinker
C (1)

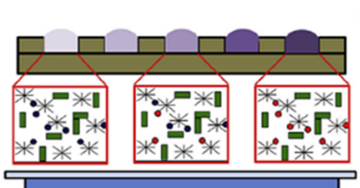

(2)

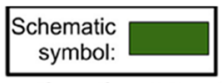

b
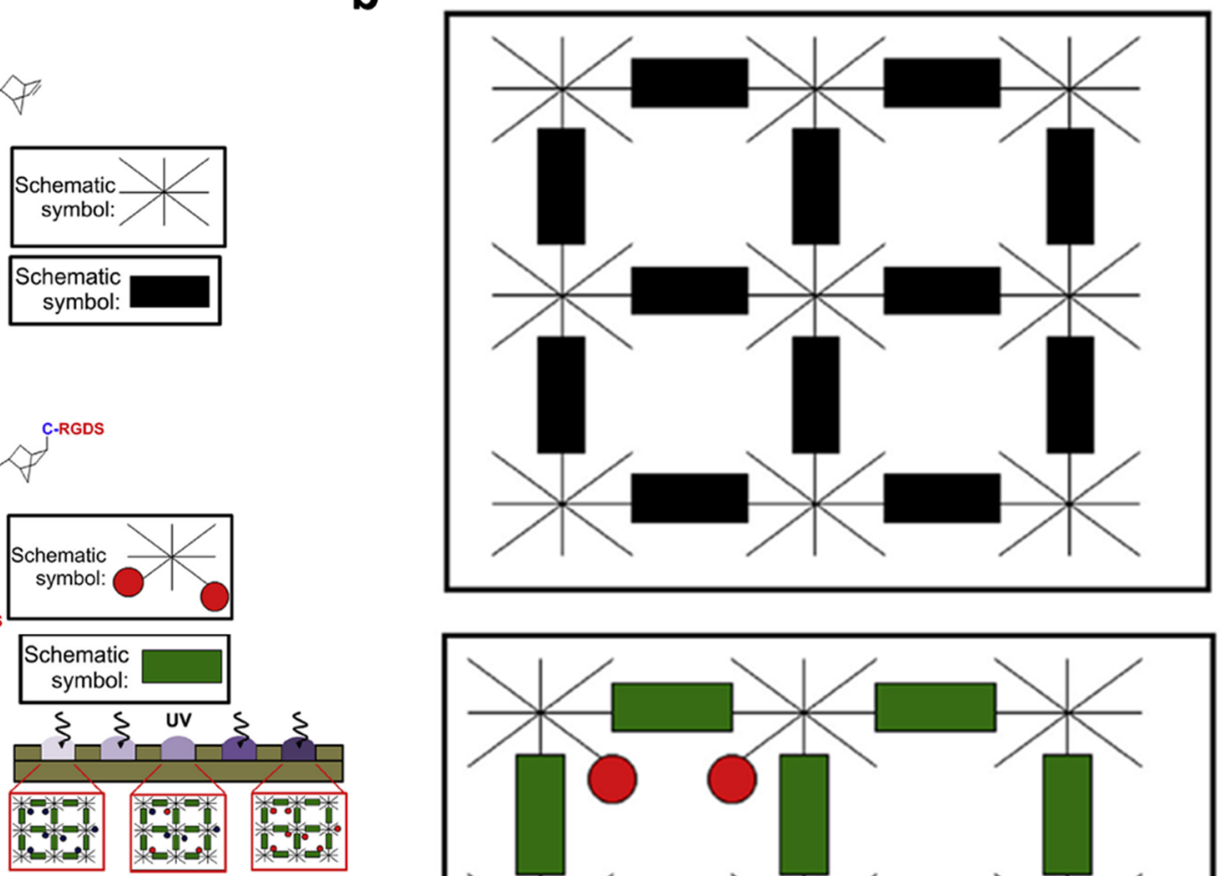

(3)

$\int^{(4)}$

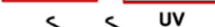

$\xi \xi$

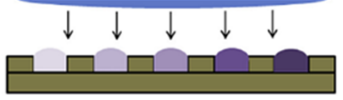

(5)
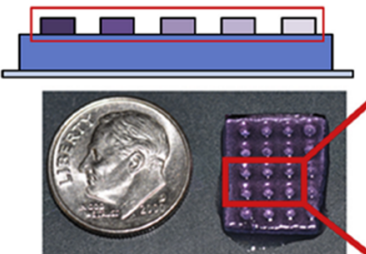

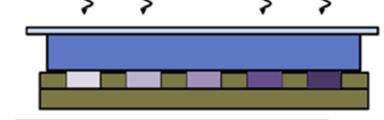

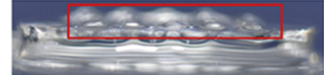

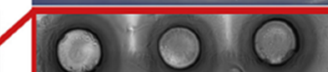




\section{Graphical Abstract}

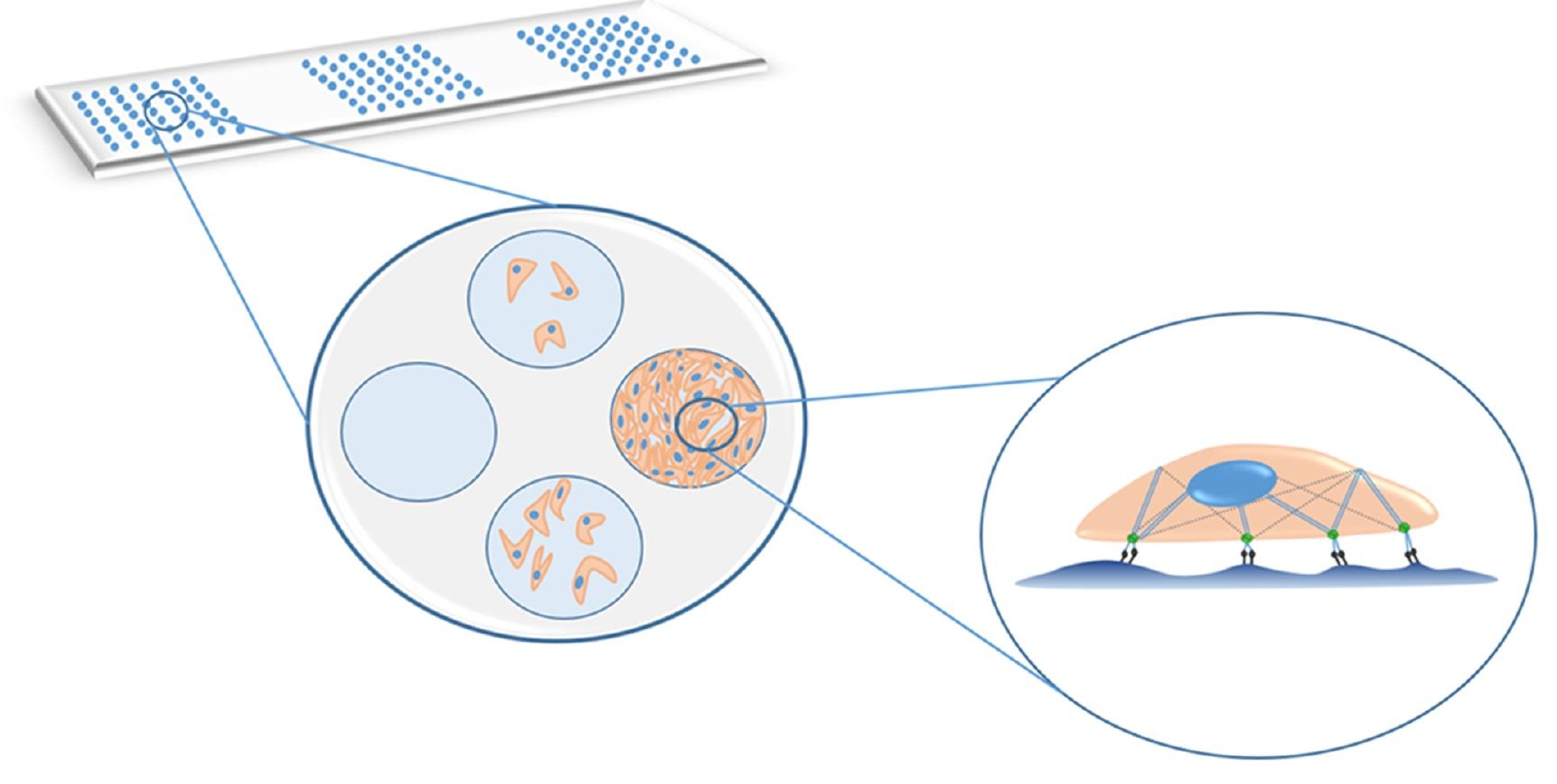

